\title{
The immunopathogenesis of cow's milk protein allergy (CMPA)
}

\author{
Giovanna Vitaliti*, Carla Cimino, Alfina Coco, Andrea Domenico Praticò and Elena Lionetti
}

\begin{abstract}
The most frequent symptoms among the manifestations of cow milk protein allergy (CMPA) are gastrointestinal. CMPA pathogenesis involves immunological mechanisms with participation of immunocompetent cells and production of immunoglobulin E (IgE). Nevertheless, recent studies have been focused on the description of other forms of CMPA, not-mediated by IgE reactions, mostly involving the T lymphocite immune system. Thus, in this field it is important to note how different kind of cells are involved in the immunopathogenesis of CMPA, such as antigen-specific T cells, T regulatory cells, cytokines secreted by the different T lymphocite subsets, B lymphocytes, antingen-presenting cells, mast cells, that together orchestrate the complex mechanism leading to the phenotipic expression of CMPA.

The progress in the diagnosis of immunologic disorders allowed the recent literature to develop new models for immuno-mediate disorders, involving new cells (such as Treg cells) and thus allowing the acquisition of a new vision of the pathogenesis of atopic diseases.

The aim of this review is to describe the immunopathogenetic aspects of CMPA in view of these new discoveries in the immunologic field, considering the immunologic pathway at the basis of both lgE- and not-lgE mediated CMPA.
\end{abstract}

\section{Introduction}

The main role of the human gastrointestinal tract is the reduction of ingested food in simple elements that can be absorbed and used for energy production and cell growth.

In order to prevent an indiscriminate immunization, secondary to the absorption of foreign antigens through the gastrointestinal barrier, the gut has developed non specific (non-immunological) mechanisms [1], such as the intestinal mucosal barrier, the intestinal motility, secretion of mucus, gastric acidity, enzymes, and specific (immunological) factors, such as the production of secretory IgA and antigen interaction with the Gut Associated Lymphoid Tissue (GALT) [2]. As a matter of fact, in normal individuals, antigen presenting cells, mostly dendritic cells sited in the GALT, play a main role in the development of a tolerogenic response. They process the food antigen and present it on a major histocompatibility complex (MHC) class II receptor to the T cells, resulting physiologically in a status of imunologic homeostasis known as "oral tolerance" by deletion or inhibition of antigen-specific $\mathrm{T}$ cells and production of

\footnotetext{
* Correspondence: giovitaliti@yahoo.it

Bronchopneumoallergology and Cystic Fibrosis O.U., Departement of Pediatrics, University of Catania, AOU Policlinico-OVE, Via Santa Sofia 78, 95123, Catania, Italy
}

\section{() Biomed Central}

regulatory $\mathrm{T}$ cells (Treg) that suppress inflammatory responses to antigens $[3,4]$.

The pathogenic mechanism of the mucosal tolerance has not yet clarified. Recent studies have suggested that human enterocytes could play a key role capturing soluble antigens and selectively activating CD $8+\mathrm{T}$ cells with a suppressive function [5].

Another explanation could be referred to a temporary dysfunction of the protective mechanisms above described, with a loss of tolerance and sensitization to food antigens. As a matter of fact, it has been suggested that enterocytes regulate the speed and the kind of absorption of ingested antigens. On this regard it has been illustrated that mucus has a major role as a barrier to foreign antigens, and food proteins reaching the gut are partially digested by proteases and by gastric acidity so that reduced gastric acidity in infants and intake of proton pump inhibitors may play a role in the pathogenesis of food allergy [6,7].

Approximately $50 \%$ of the protein absorption takes place in the duodenum, even though the whole small bowel is involved. These protein antigens may cross the epithelial barrier by transcytosis through enterocytes or by uptake via the Microfold cells (M-cells) $[8,9]$. Food proteins may diffuse paracellularly through the epithelial layer. In this case, the enhanced permeability is probably 
the result of the action of several proinflammatory cytokines [10]. In these cases, food proteins reach the MALT in large quantities, most often leading to IgG induction and immune complexes. So, the food-adverse reactions may be immunologic, but not IgE-mediated [11].

There are literature studies evidencing that in genetically predisposed individuals sensitization of naive $\mathrm{T}$ cells will lead to a TH2 type response with secretion of cytokines [12]. In these cases a cell-mediated response determines local changes with a release of specific cytokines and activation of Th2 lymphocytes (secreting IL-4, IL5, IL10 and IL13), that promote the production of IgE and amplify the inflammatory response (eosinophils, mast cells, neutrophils and natural killers chemotaxis), causing morphological and functional alteration of the mucosa $[13,14]$.

Phenomena such as the increase of intestinal permeability and circulating immune complexes, can be associated with clinical symptoms in different organs and tissues, and this data are confirmed by the fact that increased intestinal permeability is reduced by effective elimination diet that excludes offending foods [15]. The higher incidence of food allergy in infants seems to be linked to the fact that infants are particularly prone to adverse reaction to cow's milk proteins. In newborns the digestive enzymatic activity is not fully active and the secretory IgA system is not mature [16,17], The mucosa has an increased permeability shortly after birth [18]. For these reasons the passage of undigested proteins causing a primed immune response is facilitated. However, about $2 \%$ of the ingested food proteins are absorbed in an immunologically intact form also in adults [19].

\section{The immunopathogenesis of cow's milk allergy}

The immunological mechanism that lead to the development of cow's milk allergy (or Cow's Milk Protein Allergy- CMPA) is not still clarified. There are different mechanisms that contribute to the pathogenesis and the main two described mechanisms at the basis of this disease refer to IgE- and not-IgE- reactions [20]. Nevertheless, even if these two pathogenic pathways are the main described, there is a third mechanism causing CMPA, as a third group of symptoms attributed to cow's milk allergy are unpredictably associated with IgE antibody (IgE-associated/cell-mediated disorders) [21].

IgE-mediated reactions are based on simply immunological mechanisms that are better identified than notIgE-mediated ones. Since the onset of symptoms rapidly evolves (from several minutes to several hours after the contact with the allergen), this kind of mechanism is referred as "immediate hypersensitivity". This mechanism developed in ancestors human beings to identify multicellular target parasites and to build up an immune response towards these organisms [22].
IgE-mediated CMAP is characterized by two stages: the first, of "sensibilization", develops when the immune system is programmed in an aberrant way, so that $\operatorname{IgE}$ antibodies against cow milk proteins are secreted. These antibodies bind the surface of mast cells and basophiles, and the following exposure to milk proteins triggers the "activation" phase, when IgE associated to mast cells bind allergenic epitopes sited on milk proteins and unleash a rapid release of inflammatory mediators responsible for the allergic reaction. The allergens are ingested, processed and expressed by antigens presenting cells (APC) [23].

The interaction between APC and T lymphocytes promotes the modulation and the activation of $\mathrm{B}$ lymphocytes. These latter produce IgE antibodies that interact by their Fc portion with the allergen sited on mast-cells surface. The interaction among allergens on mast-cells/basophiles and IgE antibodies promotes an intracellular signalling process with a consequent cell degranulation and a release of histamine, PAF and other inflammatory mediators [24]. It is believed that both a deficiency in regulation and a polarization of milk-specific $\mathrm{T}$ cells toward type- $2 \mathrm{~T}$ helper cells (TH2) lead to B-cell signaling to produce milk protein-specific IgE. [25,26]. Treg dysfunction plays a prominent role in lack of tolerance. It has also been shown that children outgrow their cow's milk allergy in association with the development of Treg cells $[27,28]$.

In some patients there is independent immunological tolerance to cow's milk and exercise. However, anaphylaxis occurs when exercise followed intake of food (food dependent exercise-induced anaphylaxis) $[29,30]$. The exercise may induce serum hyperosmolality which increases histamine release [31] . Other possible explanations are that exercise may trigger the reaction since it decreases serum $\mathrm{pH}$ [32], or increases gastrointestinal permeability [33].

A high percentage of children and adults does not show circulating IgE specific for cow's milk proteins and their skin prick test and serum specific IgE antibodies result negative. This occurs for the development of a not-IgE-mediated allergic disease. These reactions are characterized by a delayed set up, associated with the onset of symptoms after one hour or many days after the ingestion of cow's milk proteins. For this reason, these reactions are classified as "delayed hypersensitivity". However it is important to explain that the two reactions above described are not mutually exclusive and both can act in the same disease through different pathways [34].

The pathogenesis of non-IgE mediated reactions is supported by different theories: reactions mediated by Th1 cells, interactions between $\mathrm{T}$ lymphocytes, mast cells and neurons that alters the function of the smooth muscle and the intestinal motility [35].

It seems that there are discrepancies between the high number of natural resolution of manifestations linked to 
a not-IgE-mediated reaction during childhood and the predominance of these reactions in adulthood. This theory explains as these kind of reactions can appear later in life. On this regard, Zuberbier et al. observed patients of different age and they found a direct relationship between the incidence of not-IgE -mediated reactions and age. Nevertheless, other studies are needed to confirm this hypothesis [36].

\section{T lymphocytes and the induction of mucosal tolerance in CMPA}

In food allergy the fine balance between mucosal tolerance and hypersensitivity is regulated by the immune system. This complex system includes molecules with regulatory properties, such as Transforming Growth Factor Beta 1 (TGF-beta1), IL-10 and Natural Killers. TGF-beta 1 and IL-10 are actually known as tolerogenic cytokines, produced by Treg, that are cells thought to regulate the immune system [37]. Also CD4+CD25+ Foxp3+ T cells are described as important mediators for maintaining peripheral tolerance and suppressing the $\mathrm{T}$ lymphocytes proliferation [38,39].

A decreased immune response towards foreign antigens is defined as "mucosal or oral tolerance", characterized by the deletion or suppression of $\mathrm{T}$ reactive specific-antigen cells and by production of $\mathrm{T}$ regulatory cells (Treg) that suppress the inflammatory response against benign antigens [39-44]. A dysfunction on Treg cellular activity seems to be a necessary background for the spread of both reactions (IgE- and not-IgE mediated CMPA), as the induction of mucosal tolerance in children is linked with an increase of Treg lymphocytes [45].

Actually, there are studies in progress with the aim to manipulate dendritic cells (specific cells presenting the antigen) as to improve the Treg function and/or to reestablish the Th1/Th2 balance and to promote the tolerance towards food antigens [46,47].

The Treg cells are about 5-10\% of CD4+ T lymphocytes. They express the transcription factor "forkhead box" (FOXp3), that is a key gene for the generation and the maintenance of $\mathrm{T}$ lymphocytes [39]. To date, the involvement of Treg cells in the induction of oral tolerance is little known [48].

There are two distinct phases in the development of mucosal tolerance: the clonal deletion and the active suppression of the immune response, and it seems that Treg cells mediate both phases.

In vivo the depletion of anti-CD25 antibodies demonstrated that Treg play an important role in the oral sensitization to serum cow's milk protein in mice (unpublished data by B. van Esch, B. Blokhuis, G. Hofman, L. Boon, J. Garssen, L. Knipples, L. Willemsen and F. Redegeld).
Further, Gri et al. demonstrated that Treg cells directly inhibit the mast cell degranulation through cell-cell contact and secretion of IL-10. In vivo depletion or inactivation of Treg cells causes enhancement of the anaphylactic response [40].

McNeil et al. investigated the role that Treg play in modulation of the human response. The authors showed that a previous treatment with the CD25 PC61 MoAb (monoclonal Antibodies) depleted a subpopulation of Treg in mice. In addition, PC61 seemed to alter the function of the remaining regulatory $\mathrm{T}$ cell population preventing their ability to modulate autoimmune diseases [44].

In conclusion, it seems that $\mathrm{T}$ lymphocytes subsets play a key role in allergic reactions to cow's milk proteins, above all in those not-IgE mediated, and Treg cells are at the basis of oral tolerance to food allergy, so that an altered pattern of the immune system leads to all those atopic reactions, that are not explained by an IgE background [49].

\section{Probiotics and immune system: a new vision of the intestinal microbiota in CMPA}

Toll like receptor (TLRs) recognize specific bacterial surface markers of microbiota, so called PAMP (Pathogen-associated molecular patterns) [50]. Some TLR agonists may activate Treg cells while others may trigger an allergic sensitization [51]. It could be possible that in industrialized societies, a decreased microbial exposure in early life leads to T-cell dysregulation which induce allergic disorders [52]. It is therefore, of great interest the characterization of probiotics bacterial strains that protect from sensitization to food allergens.

It is demonstrated that some chains of Lactobacillus and Bifidus Bacteria may influence the immune functions through different immunological mechanisms that act on enterocytes, antigen presenting cells, Treg and $\mathrm{T}$ and B effector lymphocytes [53-55].

In the gut, commensal bacteria allow a reduction of local inflammatory reactions. A single probiotic chain is necessary to maintain the integrity of the gut barrier reducing the effect of the antigen load. Some of these effects seem to be mediated by Treg, TLR9, TLR2 and TLR4. The intestinal microbiota also promotes the production of TNF- $\alpha$ and PGE2 that interfere with the development of tolerance mediated by dendritic cells [56]. As a matter of fact, an upregulation of TNF- $\alpha$ expression was found in gastrointestinal tract and in lesional skin of patients with acute urticaria [55]. In addition, most of the children with milk-induced cutaneous symptoms who showed an increased TNF- $\alpha$ secretion from milk-stimulated PBMCs were children with urticaria [57]. On this regard, other studies showed that probiotics directly potentiate the activity of human dendritic cells in promoting the polarization towards Th1. 
Evidences show that probiotics may promote the gut immune regulation and the allergenic tolerance [46].

In animal studies, probiotic supplementation seems to induce the development of Treg. In vitro human studies also suggest an increase of cytokine production (IL10) after ingestion of probiotics. This effect is limited only to certain species, such as L. Reuteri and L. Casei but doesn't involve other species such as L. Plantarum. It is shown that L. Reiteri and L. Casei stimulate dendritic cells to increase the production of Treg cells. These latter produce high levels of IL10, inhibiting the activation of effector T lymphocytes [58,59].

These two lactobacilli are able to bind an intercellular lecitine-like adhesion molecule, specific for dendritic cells (know as non integrin grabbing molecule 3), blocking the interaction between the antibodies and these molecules $[60,61]$. Therefore probiotics show a positive effect in the induction of Treg cells.

The intestinal microbiota also influence the production of IgA in the distal intestinal tract. The gastrointestinal area plays a crucial role as integral part associated with the mucosal immune system. Currently it is widely described that $\mathrm{B}$ cells and effector $\mathrm{T}$ cells, sited in the gastrointestinal mucosa, develop also in the respiratory tract. This could explain why the intestinal microbiota can stimulate a systemic Th1 response.

It is unclear how probiotics can influence cell populations derived from bone marrow that do not pass through the intestine at any stage of maturation. In infant animals it is demonstrated that the presence of circulating monocytes mature in different ways depending on exposure to intestinal microflora. Many studies supporting the potential effects of the bone marrow showed that changes in gut microflora have a significant influence on the bone progenitor CD34cells release into circulation. Thus, a better understanding of the potential action of the intestinal microbiota is necessary for the assessment of possible causal effects and the role of probiotics as agents for prevention and therapy of atopic diseases, such as CMPA.

\section{Competing interests}

All authors declare not to have any competing interest.

\section{Authors' contribution}

All authors declare to have equally contributed to the writing of the paper, to the collection of literature references and to the building up of the paper, as far as the revision of the paper. All authors read and approved the final manuscript.

Received: 5 June 2012 Accepted: 9 July 2012

Published: 23 July 2012

\section{References}

1. Sarker SA, Gyr K: Non-immunological defence mechanism of the gut. Gut 1992, 33:987-993.

2. Kav AL, Ahern PP, Griffin NW, et al: Human nutrition the gut microbiome and the immune system. Nature 2011, 474:327-336.
3. Schmidt-Weber $\mathrm{CB}$, Blaser $\mathrm{K}$ : T-cell tolerance in allergic response. Allergy 2002, 57:762-768.

4. de Lafaille MA C, Lafaille JJ: CD4 regulatory T cells in autoimmunity and allergy. Curr Opinion Immunol 2002, 14:771-778.

5. Pabst O, Mowat AM: Oral tolerance to food protein. Mucosal Immunol 2012, 5:232-239.

6. MacPherson AJ, Slack E: The fuctional interaction of commensal bacteria with intestinal secretory IgA. Curr Opin Gastroenterol 2007, 23:673-678.

7. Hyman PE, Clarke DD, Everett SL, et al: Gastric acid secretory function in pre-term infants. J Pediatr 1985, 106:467-471.

8. Erickson RH, Kim YS: Digestion and absorption of dietary proteins. Annu Rev Med 1990, 41:133-139.

9. Brandtzaeg PE: Current understanding of gastrointestinal immunoregulation and its relation to food allergy. Ann N Y Acad Sci 2002, 964:13-45.

10. Heyman M, Desjeux JF: Cytokine-induced alteration of the epithelial barrier to food antigens in disease. Ann N Y Acad Sci 2000, 915:304-311.

11. DeMeo MT, Mutlu EA, Keshavarzian A, et al: Intestinal permeation and gastrointestinal disease. J Clin Gastroenterol 2002, 34:385-396.

12. Majamaa $\mathrm{H}$, Isolauri E: Evalution of the gut mucosal barrier: evidence for increased antigen transfer in children with atopic eczema. J Allergy Clin Immunol 1996, 97:985-990.

13. Strobel S: Immunologically mediated damage to the intestinal mucosa. Acta Paediatr Suppl 1990, 365:46-57.

14. Sabra A, Bellanti JA, Malka Rais J, et al: IgE and non-lgE food allergy. Annal Allergy Asthma Immunol 2003, 90:71-76.

15. Caffarelli C, Cavagni G, Menzies IS, et al: Elimination diet and intestinal permeability in atopic eczema: a preliminary study. Clin Exp Allergy 1993, 23:28-31.

16. Mayer L: Mucosal immunity. Pediatrics 2003, 111:1595-1600.

17. Pajno GB, Caminiti L, Ruggeri P, De Luca R, Vita D, La Rosa M, Passalacqua G: Oral immunotherapy for cows milk allergy with a weekly up-dosing regimen: A randomized single-bind controlled study. Ann Allergy Asthma Immunol 2010, 105:376-381.

18. Bresson JL, Pang KY, Walker WA: Microvillus membrane differentiation: quantitative difference in cholera toxin binding to the intestinal surface of newborn and adult rabbits. Pediatr Res 1984, 18:984-987.

19. Husby S, Foged N, Høst A, et al: Passage of dietary antigens into the blood of children with coeliac disease. Quantification and size distribution of absorbed antigens. Gut 1987, 28:1062-1072.

20. Strobel S: Immunity induced after a feed of antigen during early life: oral tolerance v. sensitisation. Proc Nutr Soc 2001, 60:437-442.

21. Caffarelli C, Baldi F, Bendandi B, Calzone L, Marani M: Pasquinelli P on behalf of EWGPAG. Cow's milk protein allergy in children: a practical guide. Ital J Pediatr 2010, 36:5.

22. Walker-Smith J: Cow's milk allergy: a new understanding from immunology. Annal Allergy Asthma Immunol 2003, 90:81-83.

23. Brandtzaeg P: Nature and function of gastrointestinal antigen-presenting cells. Allergy 2001, 56:16-20.

24. Braga M, Quecchia C, Cavallucci E, et al: T Regulatory cells in allergy. Int I Immunopatol Pharmacol 2011, 24:555-645.

25. Beyer K, Castro R, Birnbaum A, et al: Human milk-specific mucosal lymphocytes of the gastrointestinal tract display a Th2 cytokine profile. J Allergy Clin Immunol 2002, 109:707-713.

26. Schade RP, Tiemessen MM, Knol EF, et al: The cow's milk protein-specific $T$ cell response in infancy and childhood. Clin Exp Allergy 2003, 33:725-730.

27. Karlsson MR, Rugtveit J, Brandtzaeg P: Allergen-responsive CD4_CD25_ regulatory $T$ cells in children who have outgrown cow's milk allergy. J Exp Med 2004, 199:1679-1688.

28. Tiemessen MM, Van leperen-Van Dijk AG, Bruijnzeel-Koomen CA, et al: Cow's milk-specific T-cell reactivity of children with and without persistent cow's milk allergy: key role for IL-10. J Allergy Clin Immunol 2004, 113:932-939.

29. Caffarelli C, Cataldi R, Giordano S, Cavagni G: Anaphylaxis induced by exercise and related to multiple food intake. Allergy Asthma Proc 1997, 18:245-248.

30. Caffarelli C, Terzi V, Perrone F, Cavagni G: Food related, exercise induced anaphylaxis. Arch Dis Child 1996, 75:141-144.

31. Barg W, Wolanczyk-Medrala A, Obojski A, et al: Food-dependent exercise induced anaphylaxis (FDEIA): possible impact of increased basophil histamine releasability in hyperosmolar conditions. J Investig Allergol Clin Immunol 2008, 18:312-315. 
32. Azofra GJ, Sastre DJ, Olaguibel Rivera JM, et al: Exercise-induced anaphylaxis: inhibition with sodium bicarbonate. Allergy 1986, 41:471. 10

33. Pals KL, Chang RT, Ryan AJ, Gisolfi CV: Effect of running intensity on intestinal permeability. J Appl Physiol 1997, 82:571-576.

34. Osterlund P, von Willebrand M, Andersson LC, Suomalainen H: T-cell signal transduction in children with cow's milk allergy - increased MAP kinase activation in patients with acute symptoms of cow's milk allergy. Pediatr Allergy Immunol 2003, 14:163-168.

35. Lee SH, Noh G, Lee $\mathrm{S}$, et al: Clinical characterist of oral tolerance induction of $\lg E$ mediated and non lgE mediated food allergy using interferon gamma. Allergy Asthma Proc 2010, 31:39-47.

36. Zuberbier $\mathrm{T}$, Edenharter $\mathrm{G}$, Worm $\mathrm{M}$, et al: Prevalence of adverse reactions to food in Germany-a population study. Allergy 2004, 59:338-345

37. Chaput N, Louafi S, Bardier A, et al: Identification of CD8 + CD25 + Foxp3+ suppressive T cells in colorectal cancer tissue. Gut 2009, 58:520-529.

38. Mahic M, Henjum K, Yaqub S, et al: Generation of highly suppressive adaptive CD8(+) CD25(+)FOXP3(+) regulatory T cells by continuous antigen stimulation. Eur J Immunol 2008, 38:640-646.

39. Couper KN, Blount DG, de Souza JB, et al: Incomplete depletion and rapid regeneration of Foxp3+ regulatory $T$ cells following anti-CD25 treatment in malaria-infected mice. J Immunol 2007, 178:4136-4146.

40. Gri G, Piconese S, Frossi B, et al: CD4 + CD25+ regulatory $T$ cells suppress mast cell degranulation and allergic responses through OX40-OX40L interaction. Immunity 2008, 29:771-781.

41. Huehn J, Polansky JK, Hamann A: Epigenetic control of FOXP3 expression: the key to a stable regulatory T-cell lineage? Nat Rev Immunol 2009, 9:83-89.

42. Kashyap M, Thornton AM, Norton SK, et al: Cutting edge: CD4 T cell-mast cell interactions alter IgE receptor expression and signaling. J Immunol 2008, 180:2039-2043.

43. Koenen $\mathrm{HJ}$, Joosten I: Antigen-specific regulatory T-cell subsets in transplantation tolerance regulatory $\mathrm{T}$-cell subset quality reduces the need for quantity. Hum Immunol 2006, 67:665-675.

44. Leonardi S, Rotolo N, Vitaliti G, Spicuzza L, La Rosa M: IgE values and T-lymphocyte subsets in children with atopic eczema/dermatitis syndrome. Allergy Asthma Proc 2007, 28:529-534.

45. Izcue A, Powrie F: Special regulatory T-cell review: regulatory T cells and the intestinal tract: patrolling the frontier. Immunology 2008, 123:6-10

46. Bell SJ, Rigby R, English N, et al: Migration and maturation of human colonic dendritic cells. J Immunol 2001, 166:4958-4967.

47. Hart AL, Lammers K, Brigidi $P$, et al: Modulation of human dendritic cell phenotype and function by probiotic bacteria. Gut 2004, 53:1602-1609.

48. Gibson GR, Roberfroid MB: Dietary modulation of the human colonic microbiota: introducing the concept of prebiotics. J Nutr 1995, 125:1401-1412.

49. Leonardi S, Del Giudice MM, La Rosa M, Bellanti JA: Atopie disease, immune system, and the environment. Allergy Asthma Proc 2007, 28:410-417.

50. Caffarelli C, Bernasconi S: Preventing necrotising enterocolitis with probiotics. Lancet 2007, 369:1578-1580.

51. Duez C, Gossett P, Tonnel AB: Dendritic cells and toll like receptors in allergy and asthma. Eur J Dermatol 2006, 16:12-16.

52. Rook GA, Brunet LR: Microbes, immunoregulation and the gut. Gut 2005 , 54:317-320

53. Miraglia Del Giudice M, De Luca MG: The role of probiotics in the clinical management of food allergy and atopic dermatitis. J Clin Gastroenterol 2004, 38:S84-\$85.

54. del Giudice MM, Leonardi S, Maiello N, Brunese FP: Food allergy and probiotics in childhood. J Clin Gastroenterol 2010, 44(Suppl 1):S22-S25.

55. Miraglia Del Giudice M, Decimo F, Leonardi S, et al: Immune dysregulation in atopic dermatitis. Allergy Asthma Proc 2006, 27:451-455.

56. Newberry RD, McDonough JS, Stenson WF, Lorenz RG: Spontaneous and continuous cyclooxygenase-2-dependent prostaglandin E2 production by stromal cells in the murine small intestine lamina propria: directing the tone of the intestinal immune response. J Immuno/ 2001, 166:4465-4472.

57. Hermes B, Prochazka AK, Haas N, et al: Upregulation of TNF- $a$ and IL-3 expression in lesional and uninvolved skin in different types of urticaria. J Allergy Clin Immunol 1999, 102:307-314.

58. Mazmanian SK, Kasper DL: The love-hate relationship between bacterial polysaccharides and the host immune system. Nat Rev Immunol 2006, 6:849-858.
59. McNeill A, Spittle E, Backstrom BT: Partial depletion of CD69 lowexpressing natural regulatory $T$ cells with the anti-CD25 monoclonal antibody PC61. Scand J Immunol 2007, 65:63-69.

60. Smits HH, Engering $A$, van der Kleij $\mathrm{D}$, et al: Selective probiotic bacteria induce IL-10-producing regulatory $\mathrm{T}$ cells in vitro by modulating dendritic cell function through dendritic cell-specific intercellular adhesion molecule 3-grabbing nonintegrin. J Allergy Clin Immunol 2005, 115:1260-1267.

61. Tsuji NM, Kosaka A: Oral tolerance: intestinal homeostasis and antigen-specific regulatory T cells. Trends Immunol 2008, 29:532-540.

doi:10.1186/1824-7288-38-35

Cite this article as: Vitaliti et al:: The immunopathogenesis of cow's milk protein allergy (CMPA). Italian Journal of Pediatrics 2012 38:35.

\section{Submit your next manuscript to BioMed Central and take full advantage of:}

- Convenient online submission

- Thorough peer review

- No space constraints or color figure charges

- Immediate publication on acceptance

- Inclusion in PubMed, CAS, Scopus and Google Scholar

- Research which is freely available for redistribution

Submit your manuscript at www.biomedcentral.com/submit
C Biomed Central 